\title{
Feasibility of postmortem examination in the era of COVID-19 pandemic: the experience of a Northeast Italy University Hospital
}

\author{
Cristina Basso ${ }^{1,2}$ (D) Fiorella Calabrese ${ }^{1,2} \cdot$ Marta Sbaraglia $^{3,4} \cdot$ Claudia Del Vecchio $^{5,6} \cdot$ Giovanni Carretta $^{7}$. \\ Annamaria Saieva $^{7}$ - Daniele Donato ${ }^{7}$. Luciano Flor $^{7}$ - Andrea Crisanti ${ }^{5,6}$ - Angelo Paolo Dei Tos ${ }^{3,4}$
}

Received: 29 April 2020 / Revised: 19 May 2020 / Accepted: 1 June 2020 / Published online: 9 June 2020

(C) Springer-Verlag GmbH Germany, part of Springer Nature 2020

\begin{abstract}
With the continuous spreading of SARS-CoV-2 and increasing number of deaths worldwide, the need and appropriateness for autopsy in patients with COVID-19 became a matter of discussion. In fact, in the COVID-19 era protection of healthcare workers is a priority besides patient management. No evidence is currently available about the real risk related to the procedure as well as to the subsequent management of the samples. We herein describe the procedure that has been used to perform the first series of postmortem examinations in the COVID center of the Padua University Hospital, Padua, Italy, after the implementation of an ad hoc operating procedure, to minimize the risk of infection for pathologists and technicians. Provided that the procedure is performed in an adequate environment respecting strict biosafety rules, our data indicate that complete postmortem examination appears to be safe and will be highly informative providing useful insights into the complex disease pathogenesis.
\end{abstract}

Keywords Autopsy $\cdot$ Biosafety $\cdot$ COVID- $19 \cdot$ Hazard group $\cdot$ Infectious disease protocols

\section{Introduction}

In early January 2020 in the city of Wuhan, the capital of Hubei (China), following an outbreak of pneumonia of unknown cause, a novel subtype of coronavirus $(\mathrm{CoV})$

$\overline{\text { Cristina Basso, Fiorella Calabrese and Angelo Paolo Dei Tos contributed }}$ equally to this work.

Cristina Basso

cristina.basso@unipd.it

Angelo Paolo Dei Tos

angelo.deitos@unipd.it

1 Cardiovascular Pathology Unit, Padua University Hospital, Padua, Italy

2 Department of Cardiac Thoracic and Vascular Sciences and Public Health, University of Padua, Padua, Italy

3 Pathology Unit, Padua University Hospital, Padua, Italy

4 Department of Medicine, University of Padua, Padua, Italy

5 Microbiology and Virology Unit, Padua University Hospital, Padua, Italy

6 Department of Molecular Medicine, University of Padua, Padua, Italy

7 Chief Medical Office, Padua University Hospital, Padua, Italy was identified [1-5]. The novel Cov, originally called 2019-nCOV, has then been named Severe Acute Respiratory Syndrome Coronavirus 2 (SARS-CoV-2). In February 2020, the World Health Organization (WHO) introduced the label coronavirus disease 2019 (COVID19). The virus from China rapidly spread over the world generating a global pandemic (https://www.who.int/ publications-detail/global-surveillance-for-humaninfection-with-novel-coronavirus-(2019-ncov)). The Advisory Committee on Dangerous Pathogens (ACDP) in UK had classified SARS-CoV-2 as group 3 of Hazard Group Definitions (HGD) (https://www.hsa.ie/eng/topics/ biological_agents/biological_agents_introduction/ classification_of_biological_agents/interim_statement_ covid_19_virus.pdf), namely, a pathogen that may lead to severe human disease and can represent a significant risk to employees, can spread to other humans, and prophylaxis and/or treatment are generally accessible.

The WHO, the Center for Disease Control (CDC), the Scientific Societies, the National Ministries of Health, the Regional Health Systems, and the Chief Medical officers not only provided guidance on patient management in different settings but also focused the attention on the protection of healthcare workers with a large number of documents and dedicated operating procedures. 
With the continuous spreading of SARS-CoV-2, the number of deaths increased worldwide. Thus, the need and appropriateness for autopsy in patients with COVID-19, with the inherent risk-benefit ratio, became a matter of discussion.

Hazard Group Definition is a key parameter in identifying the potential risk also for the health of mortuary staff and pathologist/ forensic physicians. The limited knowledge regarding the pathological findings of this novel disease represents the main rationale to justify postmortem examination. Nonetheless, in the absence of sound evidences regarding the degree of infectivity of cadavers, the Italian Ministry of Health has raised concerns regarding the safety of this procedure as to indicate that if a death is believed to be due to confirmed COVID-19, there is any need for a postmortem examination [6].

Human-to-human transmission of SARS-CoV-2 occurs by close contact, in particular through respiratory droplets. This modality of transmission does not apply to a postmortem procedure. However, albeit less frequently, it is postulated that transmission may occur via the contamination of inanimate surfaces from activated virus. Even if there exists not much evidence when dealing with COVID-19, studies on related viruses such as MERS and SARS demonstrated persistence until 9 days on metallic, glassy, or plastic surfaces [7]. Nonetheless, complete inactivation could be achieved by disinfection with $62-71 \%$ ethanol, $0.5 \%$ hydrogen peroxide, and $0.1 \%$ sodium hypochlorite [7]. Application of UV radiation for $60 \mathrm{~min}$ also seems to result in complete inactivation of viral infectivity [8].

It is currently accepted that formalin fixation at room temperature inactivates SARS-CoV-2 within $24 \mathrm{~h}$ [9]. Moreover, the process of paraffin embedding that occur at high temperature $\left(60-65^{\circ} \mathrm{C}\right)$ seems to contribute to virus inactivation [10]. Regarding postmortem examinations of patients died of COVID-19 infection, no evidence is currently available about the real risk related to the procedure as well as to the subsequent management of the samples [10-12]. At the time of this writing and revising (mid of May 2020), we are aware of few published European report of complete autopsies on decedents affected with COVID-19 in the English literature [13, 14].

We herein describe the procedure that has been used to perform the first series of postmortem examinations in the COVID center of the Padua University Hospital, Padua, Italy, after the implementation of an ad hoc operating procedure in the hospital, to minimize the risk of infection for pathologists and technicians.

\section{Materials and methods}

Autopsy workflow Postmortem examination of COVID-19 cases was performed in the autopsy suite of the two Pathology Units of the Padua University Hospital, Padua, Italy.
In keeping with Center for Disease Control (CDC) indications (https://www.cdc.gov/coronavirus/2019-ncov/hcp/guidancepostmortem-specimens.html), Ministry of Health [6], National Society for Pathological Anatomy (SIAPEC, https://www. siapec.it/public/uploads/archiviodocumenti/PRD\%20COVID19-9\%20rev001\%20010420.pdf), and Padua University Hospital internal Operative Procedure, postmortems were performed in an autopsy suite, the ventilation system of which could provide 6 complete air changes/h $(\mathrm{ACH})$ in a pressurenegative environment, with air exhausted through HEPA filters [Biosafety Level 3 (BSL3)].

The autopsy suite is isolated and linked to the clean area by a "filter" room aimed to avoid any chance of transferring potentially contaminated material. Automated doors in between clean areas, isolation room, and autopsy suite are kept closed during postmortem procedure and immediately after entry and egress. Good ventilation is guaranteed in the autopsy table and dissection bench.

All necessary but essential equipment to hand was already in the autopsy suite to avoid the need to find missing items and to leave and re-enter the workplace. Containers for all organ and tissue sampling with formalin and other fixative were also prepared in advance and available in the autopsy suite (Fig. 1). An oscillator saw with suction extraction of the bone aerosol into a removable chamber was used for sawing the skull (Fig. 2). All other universal precautions in autopsy dissection practice were used. A checklist for all the steps and a video camera to record external and internal examination were also available.

Bodies enter the autopsy suite contained in a double impermeable body bag. The body is then transferred to the cutting table within the inner bag. All procedures were performed within the inner bag. At the end of the procedure, the inner bag is closed and transferred to the outer bag. Before leaving the autopsy suite, the outer bag is wiped with $0.5 \%$ sodium hypochlorite/ disinfectant.

Morgue workers performing autopsies on the bodies of people who are known to have COVID-19 at the time of their death are listed in the very high exposure risk category. As such, according to national and international recommendations, to minimize the risk of infection, a specific training of the involved professionals was carried out, aimed to sensitize to the best use of the specific personal protective equipment (PPE) (Fig. 3). The use of PPE was organized as follows:

1. Following accurate washing of hands, operators wear a first pair of surgical gloves, shoe covers, and head cover

2. Operators wear a Tyvek chemical protection coverall (Cat. III) and leg covers

3. Operators wear a second pair of surgical gloves before wearing a filtering face piece 3 (FFP3) protective face mask and protective plastic goggles 

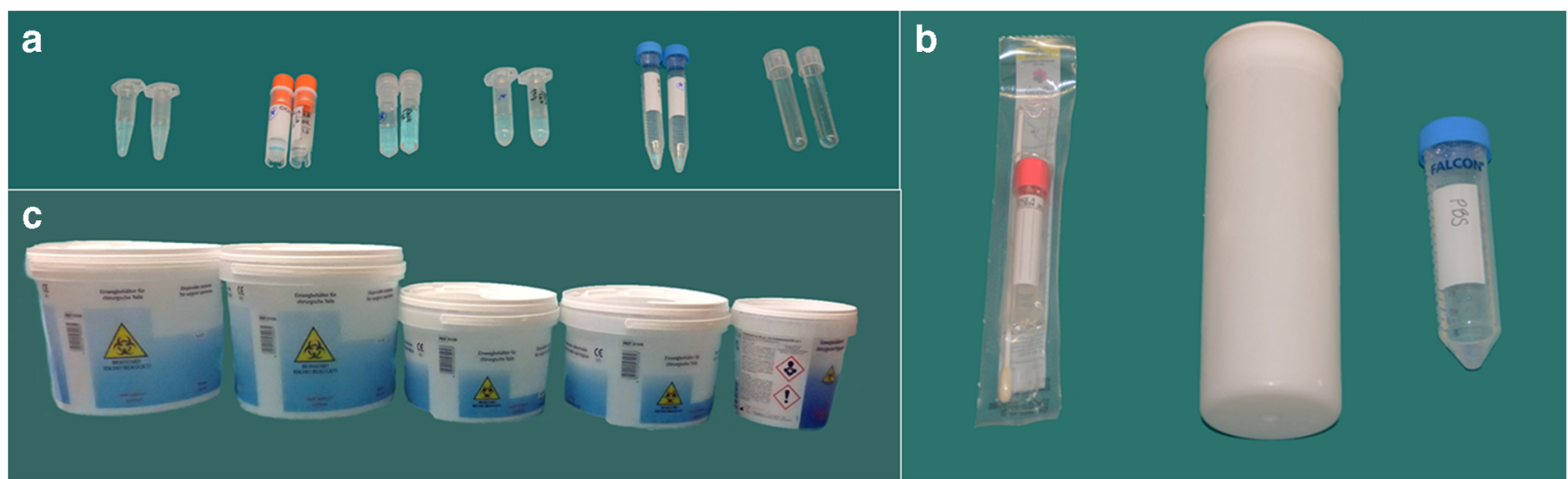

Fig. 1 Containers for whole organs and tissue sampling with formalin and other fixative available in the autopsy suite for a COVID-19 postmortem examination. a Distinct test tubes filled with Karnovsky's fixative and RNA later (recognizable based on shape or cap's color, for kidney, heart, lungs, liver, skeletal muscle, brain): two fragments $0.5 \mathrm{~cm}$

4. The Tyvek chemical protection coverall is closed. Eventually, an impermeable apron, a third pair of surgical gloves, and a fourth pair of nitrile gloves are worn

In consideration of the potential risk, we limited the number of personnel working in the autopsy suite to three people, i.e., the pathologist working in the body, the clean pathologist acting as "circulator," and the technician. The team performing postmortem examinations consisted of three alternating expert pathologists $(\mathrm{CB}, \mathrm{FC}, \mathrm{ADT})$ and two dedicated specifically trained technicians. Pathology trainees were not involved. To minimize the risk of incidental cutting, one single operator was allowed to work in the body cavity at any given time. A full organ autopsy examination was performed including appropriate sampling, storage, and preservation for different types of analysis.

The organs and tissue harvested (listed in Table 1) for histopathologic examination as a whole or fragments were all

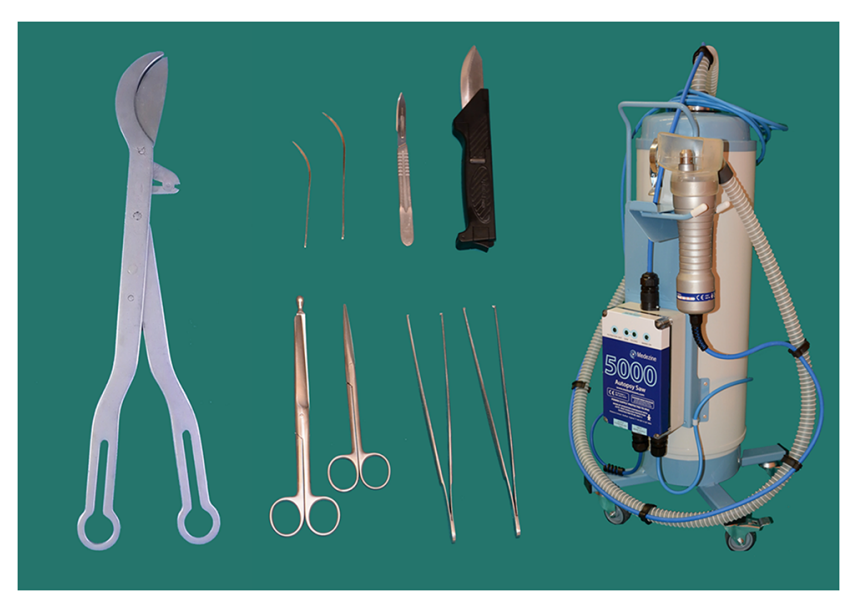

Fig. 2 Essential instruments available in the autopsy suite for a COVID19 postmortem examination in size were placed in Karnovsky solution, whereas 1 fragment $1 \mathrm{~cm}$ in size was placed in RNAlater. b Endobronchial swab and saline phosphate buffer tube for lung tissue molecular and cultural analysis. c Five jars filled with $10 \%$ formalin (lungs, liver-spleen-kidney, heart, brain and multiorgan sampling), were used for the specific tissue samples

fixed in $10 \%$ formalin solution with a final formaldehyde concentration of $4 \%$. Paraformaldehyde-glutaraldehyde solution (Karnovsky's fixative) was used for electron microscopic analysis and RNA stabilization solution (RNA later) for molecular analysis. Distinct test tubes filled with Karnovsky's fixative and RNA later (recognizable based on shape or cap's color) were used for the specific organ/tissue samples (Fig. 1). This allowed performing the first disinfection of each tubes without jeopardizing correct sample identification. One endobronchial swab and fragments of lung tissue placed in saline phosphate buffer were systematically sent the Microbiology and Virology Unit, Padua University Hospital, Padua, Italy, for molecular and cultural analysis. Lungs, heart, liver, kidney, spleen, and brain where removed and placed in formalin within rigid plastic containers. All procedures were recorded on digital devices.

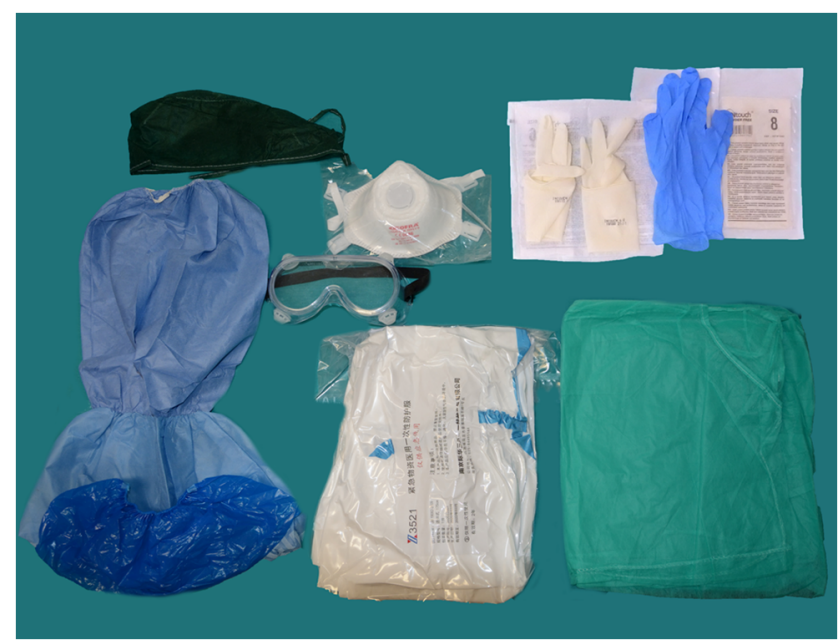

Fig. 3 Personal protective equipment (PPE) used for a COVID-19 postmortem examination. Head cover, shoes cover, leg cover, Tyvek chemical protection coverall (Cat. III), impermeable gown, plastic protective goggles, 3 pairs of surgical sterile gloves, 1 pair of powderfree nitrile gloves, FFP3 protective face mask 
Table 1 List of tissues and organs harvested; checklist in the autopsy suite

\begin{tabular}{llll}
\hline $\begin{array}{l}\text { Organs and } \\
\text { tissues }\end{array}$ & $\begin{array}{l}\text { Harvesting } \\
\text { for histology, } \\
\text { whole organ }\end{array}$ & $\begin{array}{l}\text { Harvesting } \\
\text { 1 sample }\end{array}$ & $\begin{array}{l}\text { Additional samples } \\
(\mathrm{R}=\mathrm{RNALater} \\
\mathrm{K}=\text { Karnowski; } \\
\mathrm{C}=\text { Culture })\end{array}$ \\
\hline Brain & + & & $2(\mathrm{R}+\mathrm{K})$ \\
Heart & + & & $2(\mathrm{R}+\mathrm{K})$ \\
Lungs & + & $3(\mathrm{R}+\mathrm{K}+\mathrm{C})$ \\
Liver & + & & $2(\mathrm{R}+\mathrm{K})$ \\
Kidney & + & & $2(\mathrm{R}+\mathrm{K})$ \\
Spleen & + & & \\
Trachea & - & 1 & \\
Adrenal & - & 1 & \\
Esophagus & - & 1 & \\
Stomach & - & 1 & \\
Small bowel & - & 1 & \\
Large bowel & - & 1 & \\
Bone marrow & - & 1 & \\
Skin & - & 1 & \\
Aorta & - & 1 & \\
Lymph node & - & 1 & $\mathrm{R})$ \\
Skeletal muscle & - & 1 & \\
\hline
\end{tabular}

In case of macroscopic gross findings or clinical history suggestive for other organs involvement, additional sampling is carried out

After completion of postmortem examination, all the test tubes as well as all containers are disinfected using an alcoholbased solution by the technician and then placed in larger containers. Then, the nitrile gloves, the first pair of surgical gloves, and the impermeable apron are removed inside the autopsy suite and placed in an appropriate waste receptacle. Operators then enter the filter room and, following disinfection with alcohol-based solution of gloved hands, remove the Tyvek chemical protection coverall, leg covers, plastic goggles, and the second pair of surgical gloves. Plastic goggles are placed in alcohol-based disinfection solution. All nonreusable PPEs are placed in an appropriate waste receptacle. Following disinfection of gloved hands, operators enter the clean area. In the clean area, shoe covers are removed. Operators disinfect again gloved hands and then remove hat cover and the FFP3 protective. The last pair of gloves is then removed, and hands washed with soap and water for a minimum of $20 \mathrm{~s}$.

At the end of the procedure, the autopsy suite and the filter room undergo an extensive process of disinfection. At the end of disinfection, all containers are placed in plastic bags and transferred outside the autopsy suite.

All operators have been periodically tested for COVID-19 through molecular analysis of viral RNA of nasopharyngeal swabs.
Processing of tissue samples After $24 \mathrm{~h}$ of fixation in buffered formalin, digital pictures were taken to record the gross features of main organs and further sectioning was performed to allow better fixation. After $72 \mathrm{~h}$, the organs were weighted and after sectioning and sampling, all specimens were then processed according to standard histologic processing procedure in a dedicated tissue processor. Our protocol included a total number of 17 samples (three samples per lobe + one at the hilum) for the lungs, 21 samples (18 samples covering two circumferential cross sections of the heart plus 3 coronary artery segments) for the heart, two samples of the liver, four samples of the kidneys (two per two), one-two samples of the spleen, four samples of the brain, besides other single organ/ tissue sampling as detailed in Table 1. Other regions of specific interest were sampled, if applicable.

The workflow of tissue processing for histology, immunohistochemistry, electron microscopy, and molecular analysis is reported in details in Fig. 4.

\section{Results}

In the time interval February-April 2020, 59 patients died of COVID-19 infection at the University Hospital, Padua, Italy. A total of 22 postmortem examinations ( 7 female patients, age range $61-96$, mean $80.6 \pm 8.4$ years) were carried out for an autopsy rate of $39 \%$.

Time from death to postmortem examination was ranging from 1 to 6 days (median 3 days). Endobronchial swabs were positive for SARS-CoV-2 by RT-PCR in all cases independently from timing of postmortem examinations. Viral cultures demonstrated vital virus in lung samples obtained in the patient who had postmortem examination 6 days after death.

Quality of histopathological and ultrastructural specimen was optimal despite relatively long time between death and postmortem examination. The relatively longer time of formalin fixation did not affect the quality of histology and immunostainings of paraffin-embedded tissue.

None of the operators either in the autopsy suite or in the histopathology lab developed symptoms related to COVID19 at a median interval of 16 days from postmortem examination, and all nasopharyngeal swabs proved to be repeatedly negative.

\section{Discussion}

Postmortem examination has played a key role in the development of modern medicine based on epicritic evaluation of diseased organs and clinic-pathologic correlations. From the historic standpoint, the University of Padua in the eighteenth century has represented the epicenter of this cultural revolution $[15,16]$. Since then, despite the evolution of imaging techniques, postmortem examination has kept a key role in 


\section{WORKFLOW COVID-19 POSTMORTEM EXAMINATION}

\begin{tabular}{|c|c|c|c|c|}
\hline 0 & $24 \mathrm{~h}$ & $72 \mathrm{~h}$ & 3-6 days & 7-10 days \\
\hline $\begin{array}{l}\text { Postmortem } \\
\text { examination by a team } \\
\text { of up to three people } \\
\text { ( } 2 \text { pathologists and } 1 \\
\text { technician) }\end{array}$ & $\begin{array}{l}\text { Sectioning of organs } \\
\text { taken in whole or in } \\
\text { part } \\
\text { Sampling for IHC } \\
\text { Snap-freeze processing } \\
\text { of the sample in } \\
\text { RNAlater after } 24 \mathrm{~h} \text { at } \\
4^{\circ} \mathrm{C} \\
\text { Embedding in EPON } \\
\text { and acrylic resins (LR } \\
\text { white) of samples fixed } \\
\text { in Karnowsky solution }\end{array}$ & $\begin{array}{l}\text { Sampling of } \\
\text { the organs } \\
\text { fixed in } \\
\text { formalin }\end{array}$ & $\begin{array}{l}\text { Preparation of the } \\
\text { histological sections } \\
\text { stained in } \\
\text { Hematoxylin \& Eosin } \\
\text { Cutting of the } \\
\text { samples embedded } \\
\text { in EPON and acrylic } \\
\text { resins (LR white) for } \\
\text { the preparation of } \\
\text { semi-thin sections } \\
\text { stained in toluidine } \\
\text { blue }\end{array}$ & $\begin{array}{l}\text { Preparation of } \\
\text { ultrathin sections } \\
\text { Preparation of } \\
\text { histochemical and } \\
\text { IHC reactions } \\
\text { required for the } \\
\text { histological sections }\end{array}$ \\
\hline
\end{tabular}

Fig. 4 Flowchart for tissue processing in COVID-19 postmortem examination. After $24 \mathrm{~h}$, samples, placed in RNAlater and kept at $4{ }^{\circ} \mathrm{C}$, are snap frozen and stored at $-80^{\circ} \mathrm{C}$ in a dedicated freezer. Samples fixed in Karnovsky fixative solution were embedded in both EPON and acrylic resins (LR white). After 3-6 days, tissue blocks were cut $4 \mu \mathrm{m}$ thick and stained with hematoxylin and eosin for microscopic examination.

several fields of human disease, particularly in the areas of cardiovascular diseases and infectious disease, allowing for instance significant progresses in the elucidation of pathogenetic mechanisms underlying sudden death [17], prion disease [18], Alzheimer disease [19], perinatal mortality [20], and sudden infant death syndrome [21]. The opportunity of performing postmortem examination of patients deceased for COVID-19 virus infection has raised significant concerns motivated by the potential risk of infectivity, to the extent that the Italian Ministry of Health has issued a recommendation that in principle tends to discourage from performing autopsies [6]. Our institution represents one of the main Italian centers involved with the treatment of COVID-19 patients with 460 patients hospitalized, 88 of which are in intensive care unit. A total number of 59 patients died of COVID-19 infection in our institution between February and April 2020. Despite the evidences generated by the Chinese epidemics [2,3], several aspects of COVID-19 disease are still unclear. Among them, the real extent of the involvement of organs other than lungs, the mechanism generating lung injury [onset of acute respiratory distress syndrome (ARDS) seems not to occur in all patients], the actual role of mechanic ventilation in the evolution of disease, the effect of the state of hypercoagulability, and the real impact of comorbidities and multiorgan injury in COVID19 [22]. Furthermore, autopsy is the only chance to provide tissues from many diseases and from many organs and tissues in the same patient.

As it has been already demonstrated in the past with HIV, SARS, and influenza pandemic, autopsy has the potential to
Semithin sections from EPON/acrylic resin embedded samples were stained with toluidine blue stain. After 7-10 days, ultrathin sections were prepared for ultrastructural examination. If necessary, histochemical and immunohistochemical stains were requested at this time. Blocks and slides are stored in our storeroom indefinitely

provide unique data for research and therapy, besides surveillance of public health [23-27].

We agree that there exists limited experience in regard of the real risk related to manipulation of COVID-19 biological specimens not generating aerosols. Recent data have shown that low or no level of viral RNA were detectable in stools (29\%), blood (1\%), and urine $(0 \%)$ samples; however, the sensitivity of analytic procedure may represent a potential bias [28]. In consideration of the potential relevance of data generated by analysis of material obtained from postmortem examination, adopting the stricter safety procedures, we performed 22 complete autopsies. Moreover, knowing that when dealing with a novel, previously unknown pathogen, guidelines tend to be rather fluid, we aimed to achieve on-field validation of the procedure developed internally (however largely based on indications from $\mathrm{CDC}$ ), in terms of feasibility and biosafety. We were fully aware of the concerns related to the use of the oscillator saw rather than a handsaw for removal of the brain because of the potential generation of infectious aerosol and dust formation. However, we utilized a suction device that allowed the extraction of the potentially contaminated material into a removable, disposable chamber that was disposed into appropriate waste receptacle. The oscillator saw and the suction device and the device were carefully sanitized following each procedure. Our data, demonstrating no contaminations among the operators involved with the postmortem examination as well as with tissue processing, indicates that adherence to the biosafety rules suggested by CDC appear adequate to ensure that a complete autopsy is performed without exposure to significant risk. This represents a valuable information as published evidence is confined to few 
cases, most often with very limited sampling [11-14, 29]. It might be argued the absence of contamination is actually related to viral inactivation in deceased patients. However, we not only proved the persistence of viral RNA in endobronchial swabs but we could also demonstrate virus vitality in viral cultures of the lung in a postmortem performed 6 days after death.

In conclusion, while a few and mostly minimally invasive autopsy studies have been published so far in COVID-19 patients, the full autopsy is the only chance to observe the systemic changes and take optimal samples to identify the cause of death. Provided that the procedure is performed in an adequate environment (BSL3 autopsy suite associated with availability of adequate PPE) respecting strict biosafety rules, our data indicate that complete postmortem examination appears to be safe and will be highly informative providing useful insights into the complex disease pathogenesis.

As a consequence, the indication to discourage from performing autopsies in COVID-19 deceased patients is not scientifically justified and may prevent from collecting relevant information both in terms of research and, even more importantly, of public health.

Acknowledgments The authors thank Miriam Boggian and Giulia Tonin for the precious technical assistance in the autopsy suite and all the technical staff of the Cardiovascular Pathology Unit, Padua University Hospital, for the invaluable support in tissue handling and preparation.

Author contributions • Dr. Basso, Calabrese, and Dei Tos conceptualized and designed the study, coordinated and supervised data collection, drafted the initial manuscript, and revised the manuscript.

- Drs Basso, Calabrese, Sbaraglia, Del Vecchio, Crisanti, and Dei Tos designed the protocol, collected data, and carried out the analyses.

- Dr. Carretta, Saieva, Donato, and Flor reviewed and approved the protocol of investigation and critically reviewed the manuscript for important intellectual content.

- All the authors approved the final manuscript as submitted and agree to be accountable for all aspects of the work.

\section{Compliance with ethical standards}

The present work fulfills the ethical requirements of autopsy study in Italy.

Conflict of interest The authors declare that they have no conflict of interest.

\section{References}

1. Lu H, Stratton CW, Tang YW (2020) Outbreak of pneumonia of unknown etiology in Wuhan, China: the mystery and the miracle. J Med Virol 92:401-402

2. Wu F, Zhao S, Yu B, Chen YM, Wang W, Song ZG, Hu Y, Tao ZW, Tian JH, Pei YY, Yuan ML, Zhang YL, Dai FH, Liu Y, Wang QM, Zheng JJ, Xu L, Holmes EC, Zhang YZ (2020) A new coronavirus associated with human respiratory disease in China. Nature. 579:265-269
3. Huang C, Wang Y, Li X, Ren L, Zhao J, Hu Y, Zhang L, Fan G, Xu J, Gu X, Cheng Z, Yu T, Xia J, Wei Y, Wu W, Xie X, Yin W, Li H, Liu M, Xiao Y, Gao H, Guo L, Xie J, Wang G, Jiang R, Gao Z, Jin Q, Wang J, Cao B (2020) Clinical features of patients infected with 2019 novel coronavirus in Wuhan, China. Lancet 395:497-506

4. Phelan AL, Katz R, Gostin LO (2020) The novel coronavirus originating in Wuhan, China: challenges for global health governance. JAMA. https://doi.org/10.1001/jama.2020.1097

5. Hui DS, Azhar IE, Madani TA et al (2020) The continuing 2019nCov epidemic threat of novel coronavirus to global health - the latest 2019 novel coronavirus outbreak in Wuhan, China. Int J Infect Dis 91:264-266

6. Indicazioni emergenziali connesse ad epidemia COVID-19 riguardanti il settore funebre, cimiteriale e di cremazione. Ministero della Salute. Direzione Generale della Prevenzione Sanitaria Ufficio 4. 0011285-01/04/2020-DGPRE-DGPRE-P

7. Kampf G, Todt D, Pfaender S, Steinmann E (2020) Persistence of coronaviruses on inanimate surfaces and their inactivation with biocidal agents. J Hosp Infect 104:246-251

8. Duan SM, Zhao XS, Wen RF, Huang JJ, Pi GH, Zhang SX, Han J, Bi SL, Ruan L, Dong XP (2003) SARS Research Team. Stability of SARS coronavirus in human specimens and environment and its sensitivity to heating and UV irradiation. Biomed Environ Sci. 16: 246-255

9. Darnell ME, Subbarao K, Feinstone SM, Taylor DR (2004) Inactivation of the coronavirus that induces severe acute respiratory syndrome, SARS-CoV. J Virol Methods. 121:85-91

10. Henwood AF (2020) Coronavirus disinfection in histopathology. J Histotechnol 1:1-3

11. Barton LM, Duval EJ, Stroberg E, Ghosh S, Mukhopadhyay S (2020) COVID-19 autopsies, Oklahoma, USA. Am J Clin Pathol. https://doi.org/10.1093/ajcp/aqaa062

12. Xu Z, Shi L, Wang Y, Zhang J, Huang L, Zhang C, Liu S, Zhao P, Liu H, Zhu L, Tai Y, Bai C, Gao T, Song J, Xia P, Dong J, Zhao J, Wang FS (2020) Pathological findings of COVID-19 associated with acute respiratory distress syndrome. Lancet Respir Med 8: $420-422$

13. Wichmann D, Sperhake JP, Lütgehetmann M, Steurer S, Edler C, Heinemann A, Heinrich F, Mushumba H, Kniep I, Schröder AS, Burdelski C, de Heer G, Nierhaus A, Frings D, Pfefferle S, Becker $\mathrm{H}$, Bredereke-Wiedling $\mathrm{H}$, de Weerth A, Paschen HR, Sheikhzadeh-Eggers S, Stang A, Schmiedel S, Bokemeyer C, Addo MM, Aepfelbacher M, Püschel K, Kluge S (2020) Autopsy findings and venous thromboembolism in patients with COVID-19: a prospective cohort study. Ann Intern Med. https://doi.org/10. 7326/M20-2003

14. Menter T, Haslbauer JD, Nienhold R, Savic S, Hopfer H, Deigendesch N, Frank S, Turek D, Willi N, Pargger H, Bassetti S, Leuppi JD, Cathomas G, Tolnay M, Mertz KD, Tzankov A (2020) Post-mortem examination of COVID19 patients reveals diffuse alveolar damage with severe capillary congestion and variegated findings of lungs and other organs suggesting vascular dysfunction. Histopathology. https://doi.org/10.1111/his.14134

15. Morgagni GB (1761) De sedibus et causis morborum per anatomen indagatis. Venice: ex Typographia Remondiniana

16. Zampieri F, Rizzo S, Thiene G, Basso C (2015) The clinicopathological conference, based upon Giovanni Battista Morgagni's legacy, remains of fundamental importance even in the era of the vanishing autopsy. Virchows Arch 467(3):249-254

17. Basso C, Aguilera B, Banner J, Cohle S, d'Amati G, de Gouveia RH, di Gioia C, Fabre A, Gallagher PJ, Leone O, Lucena J, Mitrofanova L, Molina P, Parsons S, Rizzo S, Sheppard MN, Mier MPS, Kim Suvarna S, Thiene G, van der Wal A, Vink A, Michaud K (2017) Association for European Cardiovascular Pathology. Guidelines for autopsy investigation of sudden cardiac 
death: 2017 update from the Association for European Cardiovascular Pathology. Virchows Arch 471(6):691-705

18. Ironside JW, Ritchie DL, Head MW (2017) Prion diseases. Handb Clin Neurol 145:393-403

19. Pillai JA, Appleby BS, Safar J, Leverenz JB (2018) Rapidly progressive Alzheimer's disease in two distinct autopsy cohorts. J Alzheimers Dis 64:973-980

20. Naeye RL (1972) The epidemiology of perinatal mortality. The power of the autopsy. Pediatr Clin N Am 19:295-310

21. Rizzo S, De Gaspari M, Carturan E, Paradiso B, Favretto D, Thiene G, Basso C (2020) A standardized postmortem protocol to assess the real burden of sudden infant death syndrome. Virchows Arch. https://doi.org/10.1007/s00428-020-02747-2

22. Connors JM, Levy JH (2020) Thromboinflammation and the hypercoagulability of COVID-19. J Thromb Haemost. https://doi.org/ $10.1111 /$ jth. 14849

23. Klatt EC, Nichols L, Noguchi TT (1994) Evolving trends revealed by autopsies of patients with the acquired immunodeficiency syndrome. 565 autopsies in adults with the acquired immunodeficiency syndrome, Los Angeles, Calif, 1982-1993. Arch Pathol Lab Med. 118:884-890

24. Nizami S, Morales C, Hu K, Holzman R, Rapkiewicz A (2020) Trends in mortality from human immunodeficiency virus infection, 1984-2016: an autopsy-based study. Arch Pathol Lab Med 144: $572-579$
25. Nicholls JM, Butany J, Poon LL, Chan KH, Beh SL, Poutanen S, Peiris JS, Wong M (2006) Time course and cellular localization of SARS-CoV nucleoprotein and RNA in lungs from fatal cases of SARS. PLoS Med 3:e27

26. Franks TJ, Chong PY, Chui P, Galvin JR, Lourens RM, Reid AH, Selbs E, McEvoy CP, Hayden CD, Fukuoka J, Taubenberger JK, Travis WD (2003) Lung pathology of severe acute respiratory syndrome (SARS): a study of 8 autopsy cases from Singapore. Hum Pathol 34:743-748

27. Sheng ZM, Chertow DS, Ambroggio X, McCall S, Przygodzki RM, Cunningham RE, Maximova OA, Kash JC, Morens DM, Taubenberger JK (2011) Autopsy series of 68 cases dying before and during the 1918 influenza pandemic peak. Proc Natl Acad Sci U S A 108:16416-16421

28. Wang W, Xu Y, Gao R, Lu R, Han K, Wu G, Tan W (2020) Detection of SARS-CoV-2 in different types of clinical specimens. JAMA. https://doi.org/10.1001/jama.2020.3786

29. Hanley B, Lucas SB, Youd E, Swift B, Osborn M (2020) Autopsy in suspected COVID-19 cases. J Clin Pathol 73(5):239-242

Publisher's note Springer Nature remains neutral with regard to jurisdictional claims in published maps and institutional affiliations. 